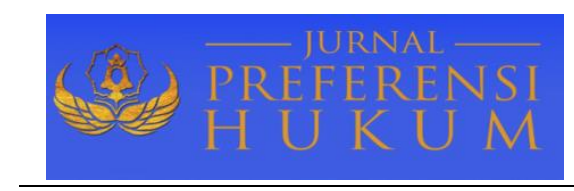

Jurnal Preferensi Hukum | ISSN: XXXX | E-ISSN: XXXX

Vol. 1, No. 2 - September 2020, Hal. 181-185| Available Online at https://www.ejournal.warmadewa.ac.id/index.php/juprehum

DOI: http://doi.org/10.22225/jph.v1i2.2384.181-185

\title{
AKIBAT HUKUM DALAM PEWARISAN DARI PELAKSANAAN PENGANGKATAN ANAK OLEH ORANG TUA TUNGGAL
}

\author{
Condro Putri Dewi Hartaka \\ Fakultas Hukum Universitas Warmadewa, Denpasar-Bali, Indonesia
}

\begin{abstract}
Abstrak
Anak adalah amanah dari Rahmat Tuhan Yang Maha Esa dan didalamnya terdapat sesuatu yang melekat sebagai harkat dan martabat sebagai pribadi seutuhnya. Seiring dengan perkembangan zaman saat ini adalah pola pikir masyarakat yang semakin maju dan berkembang, seperti orang tua yang tidak mampu membiayai masa depan anaknya dan oleh karena itu tujuan mengadopsi anak tidak hanya untuk mendapatkan anak tetapi juga untuk kesejahteraan anak-anak. Dalam konteks di Indonesia adopsi anak oleh orang tua tunggal diperbolehkan; baik orang tua angkat adalah wanita yang sudah menikah atau belum menikah atau seorang pria. Penelitian ini mengungkap proses membesarkan anak oleh orang tua tunggal dan konsekuensi hukum yang menimpa mereka. Untuk mencapai tujuan tersebut, penelitian ini dilakukan dengan menggunakan metode penelitian hukum normatif. Pengangkatan anak oleh orang tua tunggal hanya dapat dilakukan oleh Warga Negara Indonesia setelah mendapat izin dari kementerian dan pemberian izin dapat diperintahkan kepada instansi di provinsi. Adopsi oleh single parent dianggap sama dengan adopsi oleh orang tua pada umumnya. Adopsi tidak menyebabkan putusnya hubungan antara anak dengan orang tua yang sebenarnya, karena sebagian besar anak yang berada di dalam adalah dari keluarga. Pengangkatan anak harus dicantumkan dalam akta kelahiran, dengan tidak menghilangkan identitas awal. Anak asuh berhak mendapatkan penerusan dari orang tua asuh dan juga mendapatkan hak waris dari orang tua kandung.
\end{abstract}

Kata Kunci: Adopsi; Orang Tua Tunggal; Pewaris

\begin{abstract}
The child is the mandate of the Grace of God Almighty and inside there is something that is attached as the dignity and status as a whole person. Along with the time on it right now is the mindset of society as it advances and growing, such as the parents who are unable to finance the future of the child and that's why the purpose of adopting the child is not only to get the child but also for the welfare of children. In the context in Indonesia adoption of a child by single parents is permitted; either the adopting parent is a married or unmarried woman or a man. This research reveals the process of raising children by single parents and the legal consequences that occur on them. To achieve this objective, this research was conducted using normative legal research methods. Adoption of the child by single parent can only be done by the Citizens of Indonesia after obtaining permission from ministry and the granting of permission can be ordered to agencies in the province. Adoption by single parent is deemed the same with that by parents in general. Adoption does not cause the relationship between children with real parents to be disconnected, because most of the children who are in were from the family. Adoption of the child shall be listed in a birth certificate, by not eliminating the identity of the beginning. Foster child are entitled to receive succession from the foster parents and also have the inheritance rights from the real parents.
\end{abstract}

Keywords: adoption; Single Parent; Heir

\section{PENDAHULUAN}

Anak merupakan karunia dan berkah dari Tuhan Yang Maha Esa (Wiyono, 2016). Anak sebagai manusia perlu untuk tumbuh dan berkembang. Anak ialah generasi penerus bangsa dan negara, dan bahkan orang tuanya (Soekanto, 1992). Anak yang mana dikatakan sebagai generasi penerus tentu saja keberadaannya sangat diharapkan dalam sebuah keluarga, sehingga perlu dilindungi, bahkan dijaga, dan juga dibina agar dapat berkembang dan tumbuh dengan baik. Faktor ekonomi dalam kemiskinan membuat tidak sedikit anak-anak yang di terlantarkan (Pandika, 2012). Akibat kemiskinan orang tua merasa tidak sanggup untuk memenuhi hak-hak anaknya, bahkan karena takut 
menerlantarkan anaknya, ia rela menyerahkan anak kandungnya ke panti asuhan. Surat Edaran Mahkamah Agung (SEMA) Nomor 6 Tahun 1983 menjelaskan bahwa memungkinkan pria atau wanita belum menikah atau yang sudah pernah menikah dan tidak lagi terikat ikatan Perkawinan (Janda atau Duda) atau dapat dikatakan memiliki status sebagai orang tua tunggal dan merupakan Warga Negara Indonesia dapat melakukan pengangkatan anak (Soekanto, 1992).

Pengangkatan anak oleh orang tua tunggal atau dapat disebut dalam bahasa Inggris sebagai Single Parent Adoption kemudian hal ini dapat dianggap menguntungkan bagi banyak pihak, karena dapat dianggap layaknya pasangan suami istri mengangkat anak dan hal ini tentunya di landasi olehperaturanperundang- undangan dan mendapat jaminan secara hukum terhadap penyelenggaraantersebut demi untuk kesejahteraan anak (Pandika, 2012). Anak merupakan penerus cita-cita perjuangan bangsa ialah cikal bakal lahirnya suatu generasi baru bahkan anak pun dikatakan sebagai asset bangsa (Wiyono, 2016). Di tangan anak terdapat masa depan bangsa. Single Parent merupakan orang tua tunggal bahkan sebagai tumpuan keluarga, dimana orang tua tersebut juga menjadibagiandaridinamika sosial masyarakat. Di Indonesia fenomena Single Parent banyak sekali terjadi, baik ayah atau ibu entah sebab cerai atau mati, untuk membentuk proses pendewasaan keluarga. Selain Single Parent dalam hal perkawinan yang menimbulkan perceraian atau mati dalam hal mengadopsi atau mengangkat anak, laki-laki atau perempuan yang belum atau tidak menikah pun apabila melakukan adopsi atau pengangkatan anak dapat disebut pula dengan Single Parent. Hal ini pun telah dipertegas dalam Peraturan Pemerintah Nomor 54 Tahun 2007 yang mana dapat memberikan kemungkinan orang tua tunggal untuk mengadopsi anak.

Pengangkatan anak bertujuan untuk memberi status atau kedudukan yang sama seperti anak kandung kepada anak orang lain (Soeroso, 2014). Adanya anak angkat disebabkan oleh seorang mengambil anak atau di jadikan anak oleh orang lain sebagai anaknya. Penyimpangan banyak yang terjadi dalam masyarakat mengenai pelaksanaan pengangkatan anak. Pengangkatan anak banyak dilakukan dengan pemalsuan data, tanpa melalui prosedur yang benar, perdagangan anak, yang bahkan terjadi jual beli organ tubuh anak (Budiartha, 2016). Pengaturan mengenai pelaksanaan pengangkatan anak, oleh pemerintah maupun oleh masyarakat, terbentuk dalam Peraturan Pemerintah Republik Indonesia Nomor 54 Tahun 2007. Kepentingan yang terbaik bagi si anak ialah meningkatkan kesejahteraan anak, memperbaiki kehidupannya bagi masa depan si anak yang akan diangkat hal tersebut ialah tumpuan dari pada pengangkatan anak. Akibat Hukum Waris dan hak waris anak angkat dari Pengangkatan Anak terbagi dalam 3 jenis yaitu: menurut PeraturanPerundangUndangan, Hukum Islam, dan Hukum Adat (Pandika, 2012).

Berdasarkan latar belakang yang telah dijelaskan oleh penulis diatas, rumusan masalah yang akan penulis uraikan adalah sebagai berikut:

1. Bagaimana prosedur pelaksanaan pengangkatan anak oleh orang tua tunggal menurut ketentuan perundangan di Indonesia?

2. Apa akibat hukum dari pengangkatan anak oleh orang tua angkat di Indonesia?

Tujuan penelitian inilaha intuk mengetahui prosedur pelaksanaan pengangkatan anak oleh orang tua tunggal menurut ketentuan perundangan di Indonesia dan untuk mengetahui akibat hukum dalam pewarisan yang di timbulkan dari pengangkatan anak terhadap anak yang diangkat oleh orang tua tunggal.

\section{METODE PENELITIAN}

Metode penelitian adalah sekumpulan kegiatan, peraturan, dan prosedur yang digunakan oleh pelaku suatu disiplin (Marzuki, 2009). Metode penelitian ini ialah metode penelitian hukum normatif yang menganalisis suatu permasalahan hukum menurut ketentuan peraturan perundangan-undangan yang berlaku dengan menggunakan jenis pendekatan perundang-undangan serta pendekatan analisis konsep hukum (Muhammad, 2004; Marzuki, 2009). Pendekatan perundang-undangan dilakukan dengan menelaah semua undang-undang dan regulasi yang bersangkut paut dengan isu hukum yang sedang dikaji.

Dalam penelitian ini digunakan sumber bahan hukum primer, dan sumber bahan hokum sekunder. Bahan hukum primer adalah bahan hukum yang mempunyai kekuatan mengikat berupa peraturan perundang-undangan. Bahan ini mencakup peraturan perundangan mengenai perlindungan anak, pengangkatan anak, dan pelaksanaan pengangkatan anak. Bahan hukum sekunder adalah bahan 
hukum yang bersumber kepustakaan yang be rupaliteratur-literatur, dokumen-dokumen yang ada hubungannya dengan permasalahan yang di bahas, dan artikel-artikel yang ada di internet (artikel hukum).

Pengumpulan bahan hukum primer dan bahan hukum sekunder dilakukan dengan teknik menginventarisasi peraturan perundang-undangan, pencatatan, dan dikaitkan dengan jenis penelitian normatif. Analisis bahan hukum dilakukan dengan analisis deskriptif yang berupa menafsirkan dan mengkontruksikan pernyataan yang terdapat dalam dokumen; kemudian disusun dan dirangkum berdasarkan keseragamannya, serta penguraiannya dalam tulisan.

\section{HASIL DAN PEMBAHASAN}

\section{Pengertian dan Dasar Hukum Pengangkatan Anak}

Masalah pengangkatan anak banyak diperbicangkan dalam masyarakat dan telah mendapat perhatian dari pihak pemerintah. Terlihat dalam waktu terakhir ini pemerintah sangat memperhatikan mengenai adopsi atau pengangkatan anak. Dalam pembagian hukum Perdata Materiil, adopsi terletak dalam lapangan Hukum Keluarga (Soekanto, 1992; Pandika, 2012). Tidak hanya orang tua yang utuh saja dapat mengangkat anak, tetapi orang tua tunggal pun juga dapat mengangkat anak. Karena pengangkatan anak pada dasarnya ialah demi kesejahteraan anak yang diangkat; tidak peduli apakah orang tua, pria atau wanita tersebut cerai atau ditinggal mati atau belum menikah. Ketentuan mengangkat anak oleh orang tua tunggal telah di atur (Pandika, 2012), sehingga memiliki kekuatan hukum.

\section{Alasan dan Tujuan dari Pengangkatan Anak}

Pada dasarnya pengangkatan anak di dalam masyarakat Indonesia khususnya hal tersebut bukanlah hal baru atau pun masalah baru karena sejak jaman dahulu pengangkatan anak atau adopsi telah dilakukan dengan tujuan bahkan alasan yang berbeda-beda, selain untuk mempertahankan bahkan hingga melanjutkan garis keturunan dalam suatu keluarga yang tidak memiliki anak kandung, dan bahkan untuk menghindari perceraian yang akan terjadi demi untuk mempertahankan ikatan perkawinan (B. Muhammad, 1983).

Seiring perkembangan zaman, sistem hukum dan masyarakat tujuan dari adopsi telah berubah dan lebih menegaskan bahwa hal ini adalah semata-mata demi kesejahteraan anak. Tujuan dari pengangkatan anak pun bermacam-macam, ada yang untuk agar ada yang meneruskan keturunan bilamana di dalam suatu perkawinan tidak dapat memperoleh keturunan (Pandika, 2012). Ada pula di Jawa yang bertujuan sebagai pancingan seperti yakni dengan mengangkat anak maka keluarga yang mengangkat anak akan di karuniai anak kandung sendiri.

Di samping itu ada yang disebabkan oleh karena rasa belas kasihan terhadap anak yatim piatu yang disebabkan oleh keadaan orang tuanya yang tidak mampu. Di Indonesia ketentuan-ketentuan hukum mengenai pengangkatan anak perlu dipahami sampai sejauh mana hukum tersebut akan mampu melindungi kepentingan anak. Pengangkatan anak pun semakin kuat dipandang dari sisi kepentingan yang terbaik bagi si anak, terlebih untuk memperbaiki kehidupan dan masa depan dan sebagai sarana untuk kesejahteraan si anak angkat.

\section{Syarat-syarat Pengangkatan Anak menurut Ketentuan Perundangan di Indonesia}

Syarat Pengangkatan Anak diatur dalam Peraturan Pemerintah Nomor 54 Tahun 2007. Pengangkatan anak angkat oleh orang tua tunggal diatur dalam pasal 16. Persyaratan Calon Orang Tua Angkat (COTA) pada pengangkatan anak oleh orang tua tunggal diatur dalam ketentuan Bab $\mathrm{V}$ pasal 31 sampai dengan pasal 33 Peraturan Menteri Sosial Republik Indonesia No.110/HUK/2009. Tata cara pelaksanaan pengangkatan anak oleh Orang Tua Tunggal di atur dalam Pasal 34.

Di dalam pengangkatan anak melalui pengadilan terdapat 2 (dua) macam, yaitu pengangkatan anak yang peristiwa hukum pengangkatan anaknya terjadi setelah ada penetapan oleh hakim dalam sidang pengadilan, sedangkan Pengesahan Anak yaitu pengangkatan anak yang sudah terjadi atau hubungan hukum antara orang tua angkat dengan si anak angkat sudah ada.

Prosedur pengangkatan anak awalnya dimulai dengan permohonan pengangkatan anak di mana hal tersebut diajukan kepada Pengadilan Negeri dimana domisili anak yang akan di angkat tersebut. Di dalam permohonan pengajuannya harus menjelaskan alasan untuk mengangkat anak. Adapun 
untuk dapat dikabulkannya permohonan tersebut maka hakim wajib mengadakan penilaian tentang alasan dan latar belakang yang mendasari.

\section{Akibat Hukum dalam Pewarisan yang Ditimbulkan dari Pengangkatan Anak terhadap Anak yang Diangkat oleh Orang Tua Tunggal}

\section{Status dan Hubungan Anak Angkat antara Orang Tua Kandung dan Orang Tua Angkat}

Anak memiliki kedudukan yang terpenting dalam keluarga bahkan didalam masyarakat adat. Oleh orang tua, anak ialah sebagai penerus generasinya dan juga di pandang sebagai tempat harapan orang tuanya yang kelak kemudian wajib ditumpahkan. Di Jawa terdapat pengangkatan anak-anak asing atau diluar keluarga sendiri, namun sering juga pengangkatan anak kemenakan atau keponakan. Pengakatan anak dikeluarga sendiri ini bertujuan untuk memperkokoh hubungan kekerabatan.

Di Bali,jika pengangkatan anak dilakukan oleh seorang duda atau suami/istri yang tidak punya anak atau punya anak, maka persoalan di sini tidak sulit sebab sejauh ini seorang duda memang orang yang paling berhak melakukan pengangkatan anak (Artadi, 1987). Atau kalau ia duda melakukan bersama dengan janda maka ini lebih lengkap. Namun pada prinsipnya suamilah yang memegang peranan, sebab pengangkatan anak itu akan berkonsekuensi sebagai penerus atau pelanjut dari pada keturunan pihak keluarga laki-laki (suami), makadari itu kewenangan untuk ini ada pada pihak lakilaki. Sedangkan, jika seorang bujang wanita melakukan pengangkatan anak, menurut I Ketut Artadi. Hal ini tidak mungkin bisa dilakukan di Bali, sebab anak wanita di Bali tidak mewaris.

Maka dari itu jelas dengan nyata bahwa kedudukan seorang janda di Bali adalah bukan ahli waris, dan janda tentu tidak berhak melakukan pengangkatan anak karena nantinya bisa berakibat timpang yaitu tidak beralihnya hartawarisan, karena janda bukan ahli waris. Akan tetapi, jika saja perbuatan janda mengangkat anak itu adalah telah mencerminkan kehendak suaminya (misalnya pernah mendapat kuasa dari suaminya) sebelum ia meninggal, maka tindakan ini masih dimungkinkan. Hanya dengan batasan yang jelas yaitu keluarga kepurusa almarhum suami harus setuju.

\section{Hak dan Kewajiban Anak Angkat dan Orang Tua Angkat}

Setiap manusia atau masyarakat pastinya memiliki hak dan kewajiban, yang mana hal tersebut menentukan bagaimana kita seharusnya didalam bermasyarakat. Anak memiliki hakuntukhidup yang dapat dimiliki oleh setiap anak makapengaturannya harus dituangkan didalam konstitusi atau ketentuan hukum yang konkrit. Sehingga dengan prinsip-prinsip hak- hak asasi manusia itu akan memberikan jaminan keadilan dan kepastian hukum. Hak Asasi Manusia itu bersifat kodrati, bahkan walaupun tidak ada perlindungan dan jaminan konstitusional terhadap hak asasi manusia, hak itu tetap eksis dalam setiap diri manusia.

Hak anak tercantum dalam ketentuan Undang-undang Nomor 4 Tahun 1979. Selain memiliki hak, anak pun memiliki kewajiban yang telah diatur dalam Undang-undang Nomor 23 Tahun 2002. Mengenai seseorang yang diangkat sebagai anak, ia juga memiliki hak dalam rangka hukum waris, yaitu memiliki hak dan kewajiban sebagai ahli waris, baik secara material maupun immaterial.

Selain anak angkat yang memiliki hak dan kewajiban, orang tua angkat pun juga memiliki hak dan kewajibannya bahkan tanggung jawabnya sebagai orang tua. Hak orang tua angkat ada dari sejak dimulai beralihnya si anak dari kekuasaan orang tua kandungnya, atauwaliyangsahatauoranglain yang bertanggung jawab terhadap si anak ke dalam lingkungan keluarga orang tua angkat, maka berlakulah kekuasaan orang tua angkat tersebut atas anak yang diangkatnya dan akan berakhir pada saat anak itu telah dewasa atau kawin, atau karena alasan tertentu kekuasaan orang tua angkat dibebaskan atau dicabut oleh hakim.

Kewajiban dan tanggung jawab orang tua tercantum didalam Undang-undang Nomor 35 Tahun 2014. Dan pada dasarnya pengaturan mengenai kewajiban orang tua angkat atau orang tua tunggal yang mengangkat anak terhadap anak angkat sama dengan antara orang tua dan anak pada umumnya. Orang tua angkat berkewajiban untuk menjelaskan kepada anak angkatnya mengenai asal-usulnya dan orang tua kandungnya yang mana kewajibannya tercantum dalam Peraturan Pemerintah Nomor 54 Tahun 2007.

Hak dan kewajibanpun menimbulkan akibat hukum dikarenakan pengangkatan anak merupakan perbuatan hukum yaitu perbuatan yang disengaja dilakukan. Dan pelaksanaan pengangkatan anak berarti perbuatan hukum sebagai peristiwa hukum dengan akibat hukumnya berupa timbal balik 
antara orang tua angkat dengan anak angkat dan orang tua angkat dengan orang tua kandung dari anak angkat.

Pada dasarnya di Indonesia perbedaan adatistiadat menyebabkan perbedaan hukum adat waris mengikuti perbedaan sistem keluargaan, sebagaimana yang dimaksud terdapat macam sistem kekeluargaan yaitu sistem kekeluargaan Patrilineal (garis keturunan dari pihak bapak), sistem kekeluargaan Matrilineal (garis keturunan dari pihak ibu), system kekeluargaan Parental atau Bilateral (garis keturunan pihak bapak dan pihak ibu).

\section{SIMPULAN DAN SARAN}

\section{Simpulan}

1. Prosedur pengangkatan anak dan kewenangan mengangkat anak dapat dilakukan oleh seorang duda, bujangan ataupun janda, yang memungkinan bagi orang tua tunggal untuk mengangkat anak. Tetapi pada prinsipnya system kekeluargaanlah yang menentukan peranan, apakah melalui peristiwa hukum pengangkatan anaknya terjadi setelah penetapan oleh hakim dalam sidang pengadilan atau melalui pengesahan anak yang peristiwa hukumnya atas dasar hukum adat dan penetapan hakim hanya mengesahkan saja yang sudah terjadi, agar memiliki pembuktian yang kuat, sebab pengangkatan anak itu akan berkonsekuensi pada adat istiadat yang di anut untuk kelanjutan keturunan.

2. Akibat hukum pengangkatan anak oleh orang tua tunggal sama halnya seperti pengangkatan anak oleh orang tua pada umumnya dan pengangkatan anak tidak menyebabkan hubungan antara anak angkat dengan keluarga asalnya menjadi terputus.

\section{Saran}

1. Dengan semakin majunya dan pesatnya perkembangan di jaman ini sangat perlua danya perubahan dalam Hukum Nasional di bidang Pengangkatan Anak agar terjadi kepastian hukum.

2. Bagi para orang tua yang mengangkat anak, dipandang perlu untuk melakukan pengesahan pengangkatan anak. Hal tersebut untuk melindungi hak-hak anak angkat di kemudian harinya, khususnya dalam masalah pewarisan.

\section{DAFTAR PUSTAKA}

Artadi, I. K. (1987). Hukum Adat Bali dengan Aneka Masalahnya Dilengkapi Yurisprudensi. Setia Kawan.

Budiartha, I. N. P. (2016). Hukum Outsourcing. Setara Press.

Marzuki, P. M. (2009). Penelitian Hukum. Kencana Prenada Media Group.

Muhammad, A. (2004). Hukum dan Penelitian Hukum (Pertama). Citra Aditya Bhakti.

Muhammad, B. (1983). Pokok-pokok Hukum Adat. Pradnya Paramita.

Pandika, R. (2012). Hukum Pengangkatan Anak. Sinar Grafika.

Soekanto, S. (1992). Intisari Hukum Keluarga. Citra Aditya Bakti.

Soeroso, R. (2014). Perbandingan Hukum Perdata. Sinar Grafika.

Wiyono, R. (2016). Sistem Peradilan Pidana Anak di Indonesia. Sinar Grafika. 